\title{
Lipid profile of Mexican children with Down syndrome
}

\author{
Silvestre Garcia-de la Puente ${ }^{1 *}$ (D), Karla A. Flores-Arizmendi ${ }^{2} \mathbb{D}$, María J. Delgado-Montemayor ${ }^{2}$ and \\ Tania T. Vargas-Robledo ${ }^{2}$ (I)
}

\begin{abstract}
Introduction: Down syndrome (DS) is associated with various congenital anomalies and metabolic alterations, such as dyslipidemias, that can lead to cardiovascular disease in adulthood. This study was designed to describe the lipid concentrations and the frequency of dyslipidemias in children with DS.

Materials and methods: The sample included 386 patients, 52.4\% male. The study was carried out on children with DS, aged 2-18 years old, who were patients at the Mexican National Institute of Pediatrics between May 2016 and June 2017. Their height and weight were recorded, and their serum cholesterol, HDL cholesterol, and triglyceride levels were determined.

Results: Of the total patients included, 57.5\% had some type of dyslipidemia, 32.6\% isolated and 24.9\% combined. The most common alteration, considering both isolated and combined dyslipidemias, was low HDL, in 45.9\%, followed by hypertriglyceridemia, in $26.2 \%$. Among those with combined dyslipidemia, high TG with low HDL-c was the most common, in 17.9\%. A significant association was found between dyslipidemia and obesity, as well as between dyslipidemia and central obesity. The percentiles of lipid values are reported.

Conclusion: The presence of an unfavorable lipid profile is common in pediatric patients with Down syndrome, especially low HDL cholesterol and high triglycerides.
\end{abstract}

Keywords: Lipids profile, Dyslipidemia, Down syndrome, Children

\section{Introduction}

Down syndrome (DS) is the most common human chromosomopathy, with a frequency of 1 in 700 live births [1]. It is associated with congenital deformities, illnesses, and metabolic abnormalities such as dyslipidemia, with a number of studies reporting abnormal lipid concentrations in this population [2-5]. Given the increasing life expectancy of people with DS, an unfavorable lipid profile can lead to cardiovascular disease in adulthood. There have been no studies on the subject in Mexico; the objective of the current study was thus to examine

\footnotetext{
* Correspondence: garciadelapuente@hotmail.com

'Department of Research Methodology, Instituto Nacional de Pediatría, Ciudad de México, Mexico

Full list of author information is available at the end of the article
}

lipid profiles, and the frequency of dyslipidemia, in Mexican children and adolescents with DS.

\section{Materials and methods}

A prospective, observational, cross-sectional study was designed of patients with Down syndrome, aged 2-18 years, at the Instituto Nacional de Pediatría (INP), during the period from May 2016 to June 2017. A total of 386 participants were included, of which 204 (52.8\%) were male. Parents or guardians of participants provided written informed consent, and whenever possible participants themselves provided informed assent. Potential participants were excluded who had complex congenital cardiopathies, hypothyroidism under treatment, diabetes mellitus, nephrotic syndrome, chronic renal

(c) The Author(s). 2021 Open Access This article is licensed under a Creative Commons Attribution 4.0 International License, which permits use, sharing, adaptation, distribution and reproduction in any medium or format, as long as you give appropriate credit to the original author(s) and the source, provide a link to the Creative Commons licence, and indicate if changes were made. The images or other third party material in this article are included in the article's Creative Commons licence, unless indicated otherwise in a credit line to the material. If material is not included in the article's Creative Commons licence and your intended use is not permitted by statutory regulation or exceeds the permitted use, you will need to obtain permission directly from the copyright holder. To view a copy of this licence, visit http://creativecommons.org/licenses/by/4.0/ The Creative Commons Public Domain Dedication waiver (http://creativecommons.org/publicdomain/zero/1.0/) applies to the data made available in this article, unless otherwise stated in a credit line to the data. 
insufficiency, chronic malnutrition, or who were being treated with systemic steroids at the time.

Height and weight of patients at the INP Down syndrome clinic are measured routinely before each visit. Weight was measured with a Tanita BC-585F Fitscan Body Composition Monitor, in underwear, without shoes, to the nearest tenth of a kilogram. Height was measured with a Harpenden stadiometer, without shoes, in $\mathrm{cm}$ and $\mathrm{mm}$. These measurements were used to calculate body mass index $\left(\mathrm{BMI}, \mathrm{kg} / \mathrm{m}^{2}\right)$. Waist size was measured with a tape measure on the uncovered abdomen at the midpoint between the edge of the lower rib and the iliac crest, with the measurement taken after exhalation. The instruments were calibrated, and the personnel taking the measurements were standardized. All participants fasted at least $12 \mathrm{~h}$ before laboratory studies, which included the following: Hematic biometry, a general urine examination, and blood chemistry were taken. Total cholesterol (TC), HDL cholesterol (HDL-c), and triglycerides (TG) were analyzed using enzymatic methods, according to the manufacturer's specifications, with a Beckman Coulter multiplier, DxC 700 AU; LDL cholesterol (LDL-c) was calculated with Friedewald's formula: $[6,7]$ LDL $=($ CT-HDL-c- $(T G / 5))$. Non-HDL cholesterol was calculated by subtracting HDL-c from CT.

Nutritional state was classified using the BMI percentile as follows: low weight, $\mathrm{BMI}<\mathrm{p} 5$; normal nutritional state, $\mathrm{BMI} \geq \mathrm{p} 5$ and $<\mathrm{p} 85$; overweight, $\mathrm{BMI} \geq \mathrm{p} 85$ and $<$ p95; obese, $\geq$ p95 $[8,9]$. Central obesity was defined as a waist/height index $>0.50$. Lipid values were classified according to the recommendations of the Expert Panel on Integrated Guidelines for Cardiovascular Health and Risk Reduction in Children and Adolescents of the National Heart, Lung, and Blood Institute, National Institutes of Health (NIH), proposed in 1992 and modified in recent guidelines [10]. Dyslipidemia was defined as the presence of one or more of the following conditions: $\mathrm{TC} \geq 200 \mathrm{mg} / \mathrm{dL}$, LDL-c $\geq 130 \mathrm{mg} / \mathrm{dL}$, non-HDL cholesterol $\geq 145 \mathrm{mg} / \mathrm{dL}$, HDL-c $<40 \mathrm{mg} / \mathrm{dL}$, and TG $\geq 100 \mathrm{mg} /$ $\mathrm{dL}$ in children under 10 years of age or TG $\geq 130 \mathrm{mg} / \mathrm{dL}$ in children 10 years or older. With these values, dyslipidemias were classified as isolated when an abnormal value was found (high TC, LDL-c, non-HDL, and TG; low HDL-c) or combined where there were two or more abnormal values. The latter were subdivided into a) high TG and low HDL-c with normal TC and/or LDL-c, b) high TC and/or LDL-c with high TG and normal HDLc, or c) "other," any combination of two or more alterations in lipids not classified as a) or b).

\section{Statistical analysis}

The anthropometric data and lipid values are summarized with means and standard deviations, with percentiles of the lipid values for the age group 2-18 years as a whole, and also percentiles of triglyceride values for the age groups under 10 years and $10-18$ years. The categorical values, including the frequency of dyslipidemia, are summarized with frequencies and percentages. The association of dyslipidemia with obesity and central obesity was evaluated with Pearson's $\mathrm{X}^{2}$. Comparisons with the population values reported in Mexico and the United States were performed using a one-sample $\mathrm{T}$ test or binomial test. The correlation between lipid values and BMI was evaluated with Pearson's correlation.

\section{Results}

A total of 386 participants were recruited, aged 2-18 years, 204 (52.8\%) of them male. The anthropometric data and lipid values are summarized in Table 1 . The waists of only 130 were measured for the calculation of the waist/height index. Table 2 shows the lipid percentiles and Table 3 the categorical variables, including the proportion with acceptable, borderline, and abnormal lipid values; of note is that $45.9 \%$ had low HDL-c and $26.2 \%$ had high TG. Table 4 summarizes the types of dyslipidemias found: 222 (57.5\%) had dyslipidemias, 126 of them (32.6\%) isolated and (24.9\%) combined. Of the latter, the most frequent was high TG and low HDL-c with normal TC and/or LDL-c, in 69 (17.9\%). An association was found between dyslipidemia and the presence of obesity and of central obesity (Table 5), with a

Table 1 Anthropometric data and lipid values

\begin{tabular}{llll}
\hline VARIABLE & $\mathbf{n}$ & Mean & Standard Deviation \\
\hline Age (years) & 386 & 8.44 & 4.76 \\
Weight (Kg) & 386 & 25.03 & 14.35 \\
Weight percentile & 386 & 26.25 & 24.43 \\
Height (cm) & 386 & 112.29 & 22.17 \\
Height percentile & 386 & 32.89 & 28.48 \\
BMI & 386 & 18.1 & 3.8 \\
BMI percentile & 386 & 50.92 & 28.38 \\
Waist (cm) & 130 & 62.29 & 13.52 \\
Waist/height index & 130 & 0.55 & 0.09 \\
Total cholesterol & 386 & $157.23(4.07)$ & 27.7 \\
mg/dl, (mmol/L) & & & \\
Triglycerides (all) & 386 & $93.52(1.06)$ & 47.75 \\
mg/dl, (mmol/L) & & & \\
Triglycerides 2-9years & 254 & $83.01(0.94)$ & 35.57 \\
mg/dl, (mmol/L) & & & \\
$\begin{array}{l}\text { Triglycerides 10-18years } \\
\text { mg/dl, (mmol/L) }\end{array}$ & 132 & $113.76(1.28)$ & 60.25 \\
$\begin{array}{l}\text { HDL cholesterol } \\
\text { mg/dL, (mmol/L) }\end{array}$ & 386 & $41.69(1.08)$ & 10.16 \\
$\begin{array}{l}\text { LDL cholesterol } \\
\text { mg/dL, (mmol/L) }\end{array}$ & 386 & $96.62(2.5)$ & 23.26 \\
$\begin{array}{l}\text { NON-HDL cholesterol } \\
\text { mg/dL, (mmol/L) }\end{array}$ & 386 & $115.53(2.99)$ & 25.59 \\
\hline & & & \\
\hline
\end{tabular}


Table 2 Lipid Percentiles

\begin{tabular}{|c|c|c|c|c|c|c|c|}
\hline \multicolumn{8}{|l|}{ Percentiles } \\
\hline & 5 & 10 & 25 & 50 & 75 & 90 & 95 \\
\hline Cholesterol mg/dL & 112.7 & 120 & 138 & 158 & 176 & 192.3 & 203.3 \\
\hline $\mathrm{mmol} / \mathrm{L}$ & 2.91 & 3.1 & 3.57 & 4.09 & 4.55 & 4.97 & 5.26 \\
\hline Triglycerides all, mg/dL & 43 & 49.7 & 63 & 83.5 & 115 & 145.3 & 173.2 \\
\hline $\mathrm{mmol} / \mathrm{L}$ & 0.49 & 0.56 & 0.71 & 0.94 & 1.3 & 1.64 & 1.96 \\
\hline Triglycerides $2-9$ y, mg/dL & 41 & 46 & 59 & 79 & 99.25 & 122 & 136.5 \\
\hline $\mathrm{mmol} / \mathrm{L}$ & 0.46 & 0.52 & 0.67 & 0.89 & 1.12 & 1.38 & 1.54 \\
\hline Triglycerides $10-18$ y, mg/dL & 50.95 & 58 & 72.25 & 99 & 131.75 & 182.7 & 265.15 \\
\hline $\mathrm{mmol} / \mathrm{L}$ & 0.58 & 0.65 & 0.82 & 1.12 & 1.49 & 2.06 & 2.99 \\
\hline LDL cholesterol mg/dL & 59.64 & 66.97 & 80.1 & 96.65 & 112.7 & 126.26 & 135.69 \\
\hline $\mathrm{mmol} / \mathrm{L}$ & 1.54 & 1.73 & 2.07 & 2.5 & 2.91 & 3.27 & 3.51 \\
\hline $\mathrm{HDL}$ cholesterol mg/dL & 26.91 & 29.87 & 34.6 & 41 & 47.63 & 55.7 & 59.99 \\
\hline $\mathrm{mmol} / \mathrm{L}$ & 0,7 & 0.77 & 0.9 & 1.06 & 1.23 & 1.44 & 1.55 \\
\hline Non-HDL cholesterol mg/dL & 74.72 & 83.84 & 97.3 & 114.55 & 132.02 & 150.89 & 159 \\
\hline $\mathrm{mmol} / \mathrm{L}$ & 1.93 & 2.17 & 2. 52 & 2.96 & 3.41 & 3.90 & 4.11 \\
\hline
\end{tabular}

positive correlation of 0.333 between the BMI and triglycerides, $\mathrm{p}<0.001$.

\section{Discussion}

People with Down syndrome have been found to have less favorable lipid profiles than those without this condition [2-5]. Because there is little data, it has not been possible to analyze the mechanism by which children with DS develop this unfavorable profile, but genetic influence could be one of the mechanisms involved. A locus has been found in chromosome 21 , in the region $21 \mathrm{q} 11$, that carries the information for a receptor of very low density lipoproteins, and which probably plays an important role in the control mechanism of lipid metabolism in this group. A study carried out on fetuses with trisomy 21 found that they presented greater levels of cholesterol in utero than a control group [11]. A study by Buonuomo et al. [4] found that a high percentage of children with DS aged 2-18 years presented concentrations exceeding the recommendations of the Expert Panel on Integrated Guidelines for Cardiovascular Health and Risk Reduction in Children and Adolescents of the National Institutes of Health (NIH). High lipid levels in children with DS were reported in 1991 by Zamorano et al. [2] in a study carried out on 72 children with DS and a healthy control group, and in 2012 Adelekan et al. [5] confirmed that children with DS had a less favorable lipid profile than their healthy siblings. Our study found a high frequency of dyslipidemia, close to $60 \%$, comparable to the $58.3 \%$ found by De la Piedra et al. [3] in a group of 218 Chilean children and adolescents with DS.
There are few studies of the frequency of dyslipidemia in Mexican children and adolescents. Bibiloni et al., [12] in a study of 451 typically developing children aged 210 years in the state of Nuevo León, found a frequency of $54.3 \%$, similar to our result. Our participants, however, showed a greater frequency of hypoalphalipoproteinemia (low HDL-c), $45.9 \%$, versus $26.8 \%$ in their study, while other types of isolated dyslipidemia were found more often in the typically developing children. We also find a greater frequency of hypoalphalipoproteinemia in our participants than in the population of MexicanAmericans in the U.S. (45.9\% vs. $14.8 \%)$, and also a greater frequency of hypertriglyceridemia $(26.2 \%$ vs. $12.4 \%)$, though no differences in other types of hyperlipidemia [13]. The comparisons were made according to the age group, considering the reference values of lipids in Nuevo León and in the U.S.

Our results show that the most prevalent type of dyslipidemia was hypoalphalipoproteinemia (low HDL-c), in $45.9 \%$ of participants; the most prevalent of the combined dyslipidemias was high TG with low HDL-c, in $17.9 \%$. This prevalence of dyslipidemias is greater than that reported by De la Piedra for children with DS in Chile, [3] although the overall distribution of dyslipidemias is similar.

Low levels of HDL-c are generally associated with central obesity and are also related to tobacco use, physical inactivity, and diets low in monounsaturated fats. HDL-c is an excellent marker of the risk of arteriosclerosis and especially of coronary disease, and in a large number of epidemiological studies it is the lipid risk factor with the greatest predictive power: it is the most frequent lipid disorder in persons with premature coronary disease. 
Table 3 Categorical Variables for Lipids

\begin{tabular}{|c|c|c|c|}
\hline VARIABLE & $n$ & FREQUENCY & PERCENTAGE \\
\hline SEX & 386 & & \\
\hline Male & & 204 & 52.8 \\
\hline Female & & 182 & 47.2 \\
\hline CYTOGENETICS & 386 & & \\
\hline Regular Trisomy & & 297 & 76.9 \\
\hline Mosaicism & & 18 & 4.7 \\
\hline Robertsonian Translocation & & 15 & 3.9 \\
\hline Not determined & & 56 & 14.5 \\
\hline NUTRITIONAL STATE & 386 & & \\
\hline Low weight & & 20 & 5.2 \\
\hline Normal & & 307 & 79.5 \\
\hline Overweight & & 41 & 10.6 \\
\hline Obese & & 18 & 4.7 \\
\hline CENTRAL OBESITY & 130 & 93 & 71.5 \\
\hline TOTAL CHOLESTEROL & 386 & & \\
\hline Acceptable & & 259 & 67.1 \\
\hline Borderline & & 102 & 26.4 \\
\hline High & & 25 & 6.5 \\
\hline HDL CHOLESTEROL & 386 & & \\
\hline Acceptable & & 124 & 32.1 \\
\hline Borderline & & 85 & 22 \\
\hline Low & & 177 & 45.9 \\
\hline TRIGLYCERIDES & 386 & & \\
\hline Acceptable & & 171 & 44.3 \\
\hline Borderline & & 114 & 29.5 \\
\hline High & & 101 & 26.2 \\
\hline LDL CHOLESTEROL & 386 & & \\
\hline Acceptable & & 276 & 71.5 \\
\hline Borderline & & 80 & 20.7 \\
\hline High & & 30 & 7.8 \\
\hline NON-HDL CHOLESTEROL & 386 & & \\
\hline Acceptable & & 234 & 60.6 \\
\hline Borderline & & 105 & 27.2 \\
\hline High & & 47 & 12.2 \\
\hline
\end{tabular}

When low HDL-c accompanies elevated LDL-c, that is, when the LDL-c/HDL-c quotient is greater than 5 , the atherogenic risk is very high, and is doubled in the presence of hypertriglyceridemia [14]. Commonly associated medical conditions are diabetes mellitus, chronic kidney disease, and chronic inflammatory disorders like rheumatoid arthritis. Certain medications can reduce HDL-c levels, including beta blockers, thiazide-like diuretics, androgens, progestins, and probucol. The principal recommendations for treatment continue to be
Table 4 Classification of Dyslipidemias in the 386 Participants

\begin{tabular}{lll}
\hline VARIABLE & FREQUENCY & PERCENTAGE \\
\hline NO DYSLIPIDEMIA & 164 & 42.5 \\
DISLIPIDEMIA & 222 & 57.5 \\
Isolated dyslipidemia & 126 & 32.6 \\
Low HDL & 101 & 26.1 \\
Elevated triglycerides & 20 & 5.2 \\
Elevated cholesterol and/or LDL & 5 & 1.3 \\
Combined dyslipidemia & 96 & 24.9 \\
High TG and low HDL & 69 & 17.9 \\
High TG and high TC and/or LDL-c & 19 & 4.9 \\
Other combinations & 8 & 2.1
\end{tabular}

dietary; the effects of niacin (vitamin B3) on elevated levels of HDL-c have been studied [15].

There is no previous data on the frequency of overweight and obesity in the pediatric population with DS in Mexico. In our study, $10.6 \%$ of the participants were overweight and $4.7 \%$ obese, fewer than reported by Buonuomo et al. [4] There is also an important difference in the figures reported for overweight and obesity for the typically developing pediatric population of Mexico. According to the ENSANUT 2018 survey, [16] the prevalence of overweight in children aged 5-11 years is $18.1 \%$ and the prevalence of obesity is $17.5 \%$. In adolescents aged $12-19$ years, the figures are 14.6 and $23.8 \%$ respectively. Although some studies have found no correlation between the lipid profile of children with DS and their nutritional state, we found a positive correlation, with statistically significant associations between obesity and dyslipidemia $(p=.023)$ and between central obesity and dyslipidemia $(p=.029)$; we also found a positive correlation between triglyceride levels and BMI. In Mexico, Arjona-Villicaña et al., [17] in a study of 289 obese children in the state of Yucatán, found that $83.7 \%$ presented with dyslipidemia. Kavey, in a review article, mentions that combined dyslipidemia is the most prevalent lipid abnormality associated with obesity and is seen in $40 \%$ of obese adolescents [18]. Our results, by comparison, showed a low prevalence of obesity but a high prevalence of dyslipidemia.

In addition to having dyslipidemia and obesity, people with DS are often sedentary, malnourished, and are predisposed to diabetes mellitus: these factors should be

Table 5 Association of Dyslipidemia with Obesity and Central Obesity

\begin{tabular}{lllllllc}
\hline & \multicolumn{3}{l}{ DYSLIPIDIMIA } & & \\
\cline { 2 - 5 } & YES & & NO & & $\boldsymbol{p}$ & ODDS RATIO \\
\hline OBESITY & 15 & $83.3 \%$ & 3 & $16.7 \%$ & 0.023 & 3.89 \\
CENTRAL OBESITY & 62 & $66.7 \%$ & 31 & $33.3 \%$ & 0.029 & 2.36 \\
\hline
\end{tabular}


considered potential comorbidities that increase the risk of cardiovascular disease. The increased lifespan of people with DS has also changed the incidence of chronic illnesses, which creates concern for their longterm health and in particular the appearance of nontransmissible diseases like cardiovascular atherosclerosis. In the past they were considered "free of atheromas," but recent data from two large-scale studies of people with DS suggests that they may have a greater risk of mortality from ischemic cardiopathy and cerebrovascular disease than the general population $[19,20]$.

The most convincing evidence of the grouping of risk factors in young people is from Bogalusa's autopsy study, which reports the relationship between hyperlipidemia in childhood and increased cardiovascular risk in adulthood, as well as a greater percentage of fatty streaks on the surface of the aortic intima [21]. These findings regarding coronary atherosclerosis in youth provide an additional justification for the evaluation of cardiovascular risk from an early age.

Although the current guidelines for monitoring the health of children with DS emphasize the importance of preventive interventions for different conditions, there are no specific recommendations with respect to scheduled testing of the lipid profile. We suggest a systematic analysis of lipids in regular health exams from the age of 2 years, as well as specific preventive strategies including a low-fat diet, increased physical activity, and a reduction in exposure to tobacco smoke. In Table 2, we include the percentiles of lipid values, which can be used as a reference, with therapeutic measures indicated for values above the 75 th percentile for total cholesterol, triglycerides, LDL-c, and non-HDL-c, or below the 25th percentile for HDL-c.

There are no data demonstrating how cardiovascular comorbidities or risk factors in children with DS can affect the incidence of cardiovascular events; long-term monitoring is thus crucial to establish whether an unfavorable lipid profile can mean an increase in morbidity and mortality as the result of cardiovascular disease.

\section{Conclusions}

The frequency of dyslipidemia is high in children and adolescents with DS, especially of hypoalphalipoproteinemia and hypertriglyceridemia. Routine evaluation of the lipid profile is recommended in this population from the age of 2 years.

\section{Supplementary Information}

The online version contains supplementary material available at https://doi. org/10.1186/s12887-021-02542-1.

Additional file 1.

Additional file 2.
Additional file 3.

Acknowledgments

None.

\section{Study limitations}

Waist circumference and thus the waist/height index was measured only for 130 participants, and was not measured for a specific age group,

\section{Authors' contributions}

All authors contributed to the study conception and design.

Conceptualization and data curation were done by Karla A. Flores Arizmendi, investigation was done by María J. Delgado Montemayor, analysis by

Silvestre García de la Puente, and writing, review, and editing by Silvestre

García de la Puente and Tania T. Vargas Robledo. The first draft of the manuscript was written by Silvestre García de la Puente and Tania T. Vargas

Robledo. All authors read and approved the manuscript.

\section{Funding}

This work received financial support from Instituto Nacional de Pediatría, project 2016/040.

\section{Availability of data and materials}

All data generated or analyzed during this study are included in this published article [and its supplementary information files].

\section{Ethics approval and consent to participate}

This work was carried out in accordance with the World Medical Association's Helsinki Declaration, with Approval No. 2016/040 from the Research and Research Ethics Boards of the National Institute of Pediatrics, Mexico City, Mexico, registered as IRB00008064 and IRB00008065 with the Office for Human Research Protection of the NIH (http://ohrp.cit.nih.gov/ search/search.aspx). A copy of the approval is available upon request. Informed assent (where possible) of participants and the written informed consent of parents or guardians was obtained.

Consent for publication

Not applicable.

\section{Competing interests}

None.

\section{Author details}

'Department of Research Methodology, Instituto Nacional de Pediatría, Ciudad de México, Mexico. ${ }^{2}$ Pediatrician. Down Syndrome Clinic, Instituto Nacional de Pediatría, Ciudad de México, Mexico.

Received: 22 October 2020 Accepted: 27 January 2021

Published online: 13 February 2021

\section{References}

1. Parker SE, Mai $C T$, Canfield MA, et al. Updated National Birth Prevalence estimates for selected birth defects in the United States, 2004-2006. Birth Defects Res A Clin Mol Teratol. 2010;88(12):1008-16. https://doi.org/10.1002/ bdra.20735.

2. Zamorano AV, Guzman MT, Aspillaga MH, et al. Concentraciones de lipidos sericos en ninos con sindrome de Down. [Concentrations of serum lipids in Children with Down syndrome.]. Arch Biol Med Exp (Santiago). 1991;24(1): 49-55.

3. De la Piedra MJ, Alberti G, Cerda J, et al. High frequency of dyslipidemia in children and adolescents with Down syndrome. Rev Chil Pediatr. 2017;88(5): 595-601.

4. Buonuomo PS, Bartuli A, Mastrogiorgio G, et al. Lipid profiles in a large cohort of Italian children with Down syndrome. Eur J Med Genet. 2016; 59(8):392-5. https://doi.org/10.1016/j.ejmg.2016.06.005.

5. Adelekan T, Magge S, Shults J, Stallings V, Stettler N. Lipid profiles of children with Down syndrome compared with their siblings. Pediatrics. 2012;129(6):e1382-7. https://doi.org/10.1542/peds.2011-1262. 
6. Friedewald WT, Levy RI, Fredrickson DS. Estimation of the concentration of low-density lipoprotein cholesterol in plasma, without use of the preparative ultracentrifuge. Clin Chem. 1972;18(6):499-502.

7. Tremblay AJ, Morrissette H, Gagné JM, Bergeron J, Gagné C, Couture P. Validation of the Friedewald formula for the determination of low-density lipoprotein cholesterol compared with beta-quantification in a large population. Clin Biochem. 2004;37(9):785-90. https://doi.org/10.1016/j. clinbiochem.2004.03.008.

8. Cole TJ, Bellizzi MC, Flegal KM, Dietz WH. Establishing a standard definition for child overweight and obesity worldwide: international survey. BMJ. 2000; 320(7244):1240-3. https://doi.org/10.1136/bmj.320.7244.1240.

9. Cole TJ, Flegal KM, Nicholls D, Jackson AA. Body mass index cut offs to define thinness in children and adolescents: international survey. BMJ. 2007; 335(7612):194. https://doi.org/10.1136/bmj.39238.399444.55.

10. Expert Panel on Integrated Guidelines for Cardiovascular Health and Risk Reduction in Children and Adolescents; National Heart, Lung, and Blood Institute. Expert panel on integrated guidelines for cardiovascular health and risk reduction in children and adolescents: summary report. Pediatrics. 2011;128 Suppl 5(Suppl 5):S213-56. https://doi.org/10.1542/peds.2009-21 07C.

11. Bocconi L, Nava S, Fogliani R, Nicolini U. Trisomy 21 is associated with hypercholesterolemia during intrauterine life. Am J Obstet Gynecol. 1997; m J Obstet Gynecol. 1997 Mar;176(3):540-3. https://doi.org/10.1016/s0002-93 78(97)70544-1.

12. Bibiloni MDM, Salas R, Novelo HI, Villarreal JZ, Sureda A, Tur JA. Serum lipid levels and dyslipidaemia prevalence among 2-10 year-old northern Mexican children. PLoS One. 2015;10(3):1-14. https://doi.org/10.1371/journal.pone.011 9877.

13. Kit BK, Carroll MD, Lacher DA, Sorlie PD, DeJesus JM, Ogden C. Trends in serum lipids among US youths aged 6 to 19 years, 1988-2010. JAMA. 2012; 308(6):591-600. https://doi.org/10.1001/jama.2012.9136.

14. Laris EM, Arteaga LA, Cuevas MA, et al. El colesterol HDL: iun nuevo objetivo terapéutico en el manejo de las dislipidemias y la ateroesclerosis? [HDL cholesterol: A new therapeutic objective in the management of dyslipidemias and atherosclerosis?]. Rev Méd Chile. 2005;133:823-32. https:// doi.org/10.4067/S0034-98872005000700011.

15. Rader DJ, Rosas S. Management of selected lipid abnormalities. Hypertriglyceridemia, low HDL cholesterol, lipoprotein(a), in thyroid and renal diseases, and post-transplantation. Med Clin North Am. 2000;84(1):4361. https://doi.org/10.1016/s0025-7125(05)70206-6.

16. ENSANUT 2018. Encuesta Nacional de Salud y Nutrición [National Survey of Health and Nutrition] Ensanut 2018

17. Arjona-Villicaña RD, Herrera-Sánchez LF, Sumárraga-Ugalde C, Ma A-G. Asociación entre el índice de masa corporal y el perfil de lípidos en niños y adolescentes mexicanos con obesidad: un análisis retrospectivo. [Association between body mass index and lipid profile in Mexican children and adolescents with obesity: A retrospective analysis.]. Boll Med Hosp Infant Mex. 2014:71(2):88-94.

18. Kavey REW. Combined dyslipidemia in childhood. J Clin lipido. 2015;9(5): S41-56. https://doi.org/10.1016/j.jacl.2015.06.008.

19. Hill DA, Gridley $G$, Cnattingius $S$, et al. Mortality and cancer incidence among individuals with Down syndrome. Arch Intern Med. 2003;163(6):70511. https://doi.org/10.1001/archinte.163.6.705.

20. Day SM, Strauss DJ, Shavelle RM, Reynolds RJ. Mortality and causes of death in persons with Down syndrome in California. Dev Med Child Neurol. 2005; 47(3):171-6. https://doi.org/10.1017/s0012162205000319.

21. Newman WP 3rd, Freedman DS, Voors AW, et al. Relation of serum lipoprotein levels and systolic blood pressure to early atherosclerosis. The Bogalusa heart study. N Engl J Med. 1986;314(3):138-44. https://doi.org/10.1 056/NEJM198601163140302.

\section{Publisher's Note}

Springer Nature remains neutral with regard to jurisdictional claims in published maps and institutional affiliations.

Ready to submit your research? Choose BMC and benefit from:

- fast, convenient online submission

- thorough peer review by experienced researchers in your field

- rapid publication on acceptance

- support for research data, including large and complex data types

- gold Open Access which fosters wider collaboration and increased citations

- maximum visibility for your research: over $100 \mathrm{M}$ website views per year

At BMC, research is always in progress.

Learn more biomedcentral.com/submissions 